\title{
Perencanaan Hidrolis Pintu Pada Bangunan Pengambilan Air (Intake)
}

\author{
Binsar SILITONGA $^{1} \cdot$ Hendry $^{2}$
}

\begin{abstract}
The planning process of an intake water building must be conducted properly, such by considering several aspects namely topography, hydro-climatology, and also hydraulic condition of existing stream. In the planning of intake water building, the dimensions of water gate are based on the existing weir building. The Existing Dam building in this study is Sei Bingei weir. This weir was constructed to detain the flow of Bingei River. The weir is used to collect water to fill the demand of water company (PAM) Tirta Sari Binjai City.
\end{abstract}

Kata kunci: bangunan pengambilan, aspek hidrolis, aliran sungai, pintu pengambilan

\section{Latar Belakang}

Bangunan pengambilan air (intake) adalah suatu bangunan yang dibuat sedemikian rupa pada sisi suatu sumber air (umumnya adalah sungai) dengan maksud agar sebahagian air dari sungai tersebut (air baku) dapat dibelokkan untuk dimanfaatkan sesuai keinginan. Untuk pengambilan air dari sungai bisa dilakukan dengan cara mengambil langsung (menyadap) ataupun dengan cara membuat bendung pada bagian hilir (up stream) dari sungai.

Pada tulisan kali ini, lokasi bangunan pengambilan air (intake) akan direncanakan mendapatkan pasokan air baku dari Sungai Bingei Kota Binjai. Dan pada lokasi yang dimaksud sudah ada bangunan pengambilaan air yang lain yaitu bangunan pengambilan air PDAM Tirta Sari. Oleh karena itu kedua bangunan pengambilan akan saling bersisian dimana lokasi bangunan pengambilan yang baru berada di sebelah hulu (down stream) dari bangunan pengambilan air PDAM Tirta Sari. Dan kedua bangunan pengambilan ini kelak akan berada dan bersebelahan dengan Bendung Sei Bingei.

Dengan demikian, dalam perencanaannya tidak akan terlepas dari bangunan utama yang ada (eksisting), yaitu Bendung Sei Bingei. Oleh sebab itu referensi perencanaan Intake Mebidang mengacu pada data teknis Bendung Sei Bingei.

\section{Data Teknis Bendung Sei Bingei}

Bendung adalah suatu konstruksi bangunan air yang dibangun melintang badan sungai. Konstruksi nya dibuat secara melintang dengan maksud untuk mengubah karakteristik aliran sungai. Dilihat dari bentuk dan konstruksinya, Bendung Sei Bingei adalah merupakan bendung tetap. Fungsi bendung bertujuan untuk meninggikan muka air di sungai sampai pada ketinggian yang diperlukan agar air dapat dialirkan ke saluran atau ke bangunan lainnya.

\footnotetext{
${ }^{1}$ Staf Pengajar Teknik Sipil Universitas Katolik Santo Thomas

e-mail: binsar_silitong@yahoo.com

${ }^{2}$ PT. Mulya Sakti Wijaya
} 
Tabel 1. Data Teknis Bendung Sei Bingei

\begin{tabular}{|c|c|c|}
\hline NO & KETERANGAN & DATA TEKNIS \\
\hline \multirow[t]{7}{*}{ 1) } & HIDROLOGI & \\
\hline & - Luas daerah pengaliran sungai & $297 \mathrm{~km}^{2}$ \\
\hline & - Curah hujan rerata bulanan & $168,92 \mathrm{~mm}$ \\
\hline & - Curah hujan rerata tahunan & $2029 \mathrm{~mm}$ \\
\hline & - Distribusi frekwensi & Log Pearson III \\
\hline & - $\quad$ Curah hujan rancangan 100 tahun & $150 \mathrm{~mm}$ \\
\hline & - Debit banjir rancangan 100 tahun & $300 \mathrm{~m}^{3} / \mathrm{dt}$ \\
\hline \multirow[t]{18}{*}{ 2) } & BANGUNAN UTAMA BENDUNG & \\
\hline & - $\quad$ Elevasi mercu bendung & $+34,90$ \\
\hline & - $\quad$ Lebar tubuh bendung & $36 \mathrm{~m}$ \\
\hline & - $\quad$ Lebar efektif bendung & $35,40 \mathrm{~m}$ \\
\hline & - Pembilas & 2 buah@2,0 m \\
\hline & - Elevasi apron bendung & $+32,50$ \\
\hline & - Elevasi dasar sungai & $+32,90$ \\
\hline & - Panjang lantai apron & $11,80 \mathrm{~m}$ \\
\hline & - $\quad$ Tinggi bendung & $2,40 \mathrm{~m}$ \\
\hline & - $\quad$ Tinggi air banjir di hulu bendung $\left(\mathrm{Q}_{100}\right)$ & $2,32 \mathrm{~m}$ \\
\hline & - $\quad$ Tinggi air di kaki bendung (y1) & $0,74 \mathrm{~m}$ \\
\hline & - $\quad$ Tinggi air di setelah endsill (y2) & $3,78 \mathrm{~m}$ \\
\hline & - Tipe kolam olak & USBR IV \\
\hline & - Panjang kolam olak & $16,00 \mathrm{~m}$ \\
\hline & - Elevasi dasar kolam olak & $+30,30 \mathrm{~m}$ \\
\hline & - $\quad$ Tinggi blok muka & $0,80 \mathrm{~m}$ \\
\hline & - Lebar blok muka & $0,80 \mathrm{~m}$ \\
\hline & - Jarak antar blok muka & $1,90 \mathrm{~m}$ \\
\hline \multirow[t]{5}{*}{ 3) } & BANGUNAN PENGAMBILAN INTAKE PDAM TIRTA SARI & \\
\hline & - Kebutuhan air baku di intake & $250 \mathrm{Lt} / \mathrm{dt}$ \\
\hline & - $\quad$ Bangunan Pengambilan Tidak dilengkapi pintu & $\begin{array}{l}\text { namun terdapat } \\
\text { trashrack }\end{array}$ \\
\hline & - $\quad$ Lebat bangunan pengambilan & $6,50 \mathrm{~m}$ \\
\hline & - Lebar trashrack & $6,50 \mathrm{~m}$ \\
\hline \multirow[t]{5}{*}{ 4) } & PANJANG PELINDUNG DASAR SUNGAI DI HILIR BENDUNG & \\
\hline & - Kedalaman gerusan di bawah permukaan air banjir $=\mathrm{R}$ & $3 \mathrm{~m}$ \\
\hline & - Debit banjir yang melewati pelimpah (Q) & $300 \mathrm{~m}^{3} / \mathrm{dt}$ \\
\hline & - $\quad$ Faktor Lumpur Lacey (f) & 1,76 \\
\hline & - $\quad$ Panjang lindungan dari pasangan batu kosong (L) & $12 \mathrm{~m}$ \\
\hline \multirow[t]{8}{*}{ 5) } & PEMBILAS SEDIMEN DI HULU BENDUNG & \\
\hline & - $\quad$ Tinggi Bukaan Pintu Pembilas & $1,40 \mathrm{~m}$ \\
\hline & - Debit Pembilas (50\%Debit yang lewat bendung) & $20,37 \mathrm{~m}^{3} / \mathrm{dt}$ \\
\hline & - Kemiringan pembilas bendung & 0,0025 \\
\hline & - Lebar pembilasan dari dinding penahan hingga rencana dinding pemisah & $5,00 \mathrm{~m}$ \\
\hline & - $\quad$ Panjang dinding pemisah & $42,50 \mathrm{~m}$ \\
\hline & - $\quad$ Sudut dinding pemisah pembilas & $60-700$ \\
\hline & - Waktu pembilasan & 60 menit/hari \\
\hline
\end{tabular}




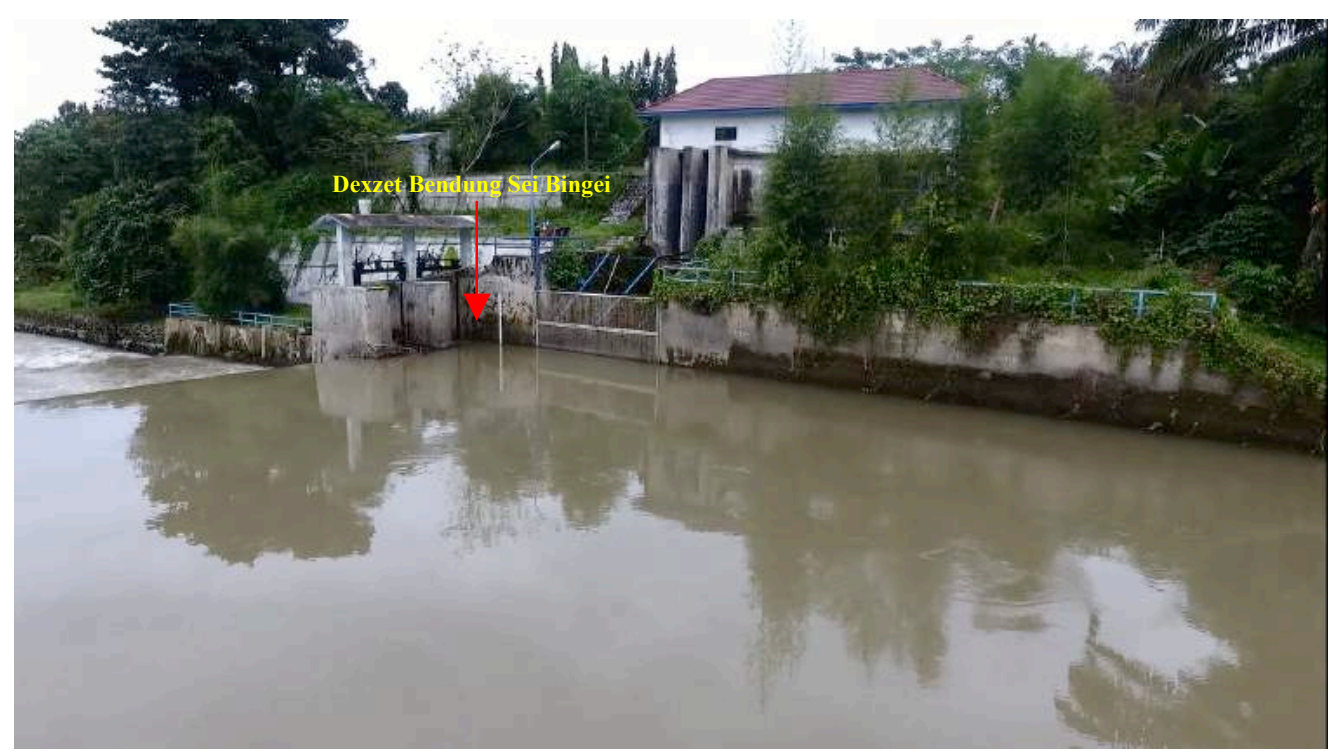

Gambar 1. Titik Referensi (Sumber : Survey Lapangan, Januari 2018)

\section{Kondisi Topografi dan Hidroklimatologi}

\section{Topografi}

Kondisi topografi wilayah pekerjaan merupakan daerah landai yang berada di sebelah hulu Intake PDAM Tirta Sari. Kegunaan dari bangunan pengambilan air ini direncanakan adalah untuk mensupplai air baku bagi Kota Medan, Kota Binjai dan Kab. Deli Serdang. Besar debit yang diharapkan adalah 2400 liter per detik dengan sumber air baku berasal dari Sungai Bingei. Adapun batas-batas wilayah yang berada di sekitar lokasi pekerjaan adalah seperti berikut :

Sebelah Utara : : Berbatasan dengan Desa Tanah Merah

Sebelah Selatan : : Berbatasan dengan Tanjung Merahe

Sebelah Barat $\quad$ : Berbatasan dengan areal PTP Padang Belakang

Sebelah Timur : : Berbatasan dengan Desa Kesatria

\section{Hidroklimatologi}

Hidroklimatologi adalah merupakan keadaan rerata cuaca suatu daerah atau tempat dalam periode (waktu) yang tertentu. Pada umumnya kondisi hidroklimatologi sangat dipengaruhi oleh letak geografis dan ketinggian daerah tersebut. Variasi iklim ini ditentukan oleh berbagai parameter, antara lain : intensitas curah hujan, hari hujan, kelembaban udara, suhu udara, kecepatan angin dan lama penyinaran matahari. Rata-rata temperatur suhu $\pm 25-27{ }^{\circ} \mathrm{C}$, kelembaban udara rata-rata bulanan $\pm 81-85 \%$, kecepatan angin $\pm 41-45 \mathrm{~km} / \mathrm{hr}$ dan Rata-rata curah hujan bulanan didaerah rencana adalah $\pm 70-300 \mathrm{~mm} / \mathrm{bulan}$.

\section{Perencanaan Bangunan Pengambilan}

Model bangunan pengambilan yang akan direncanakan dapat dilihat pada gambar yang disajikan berikut ini. 


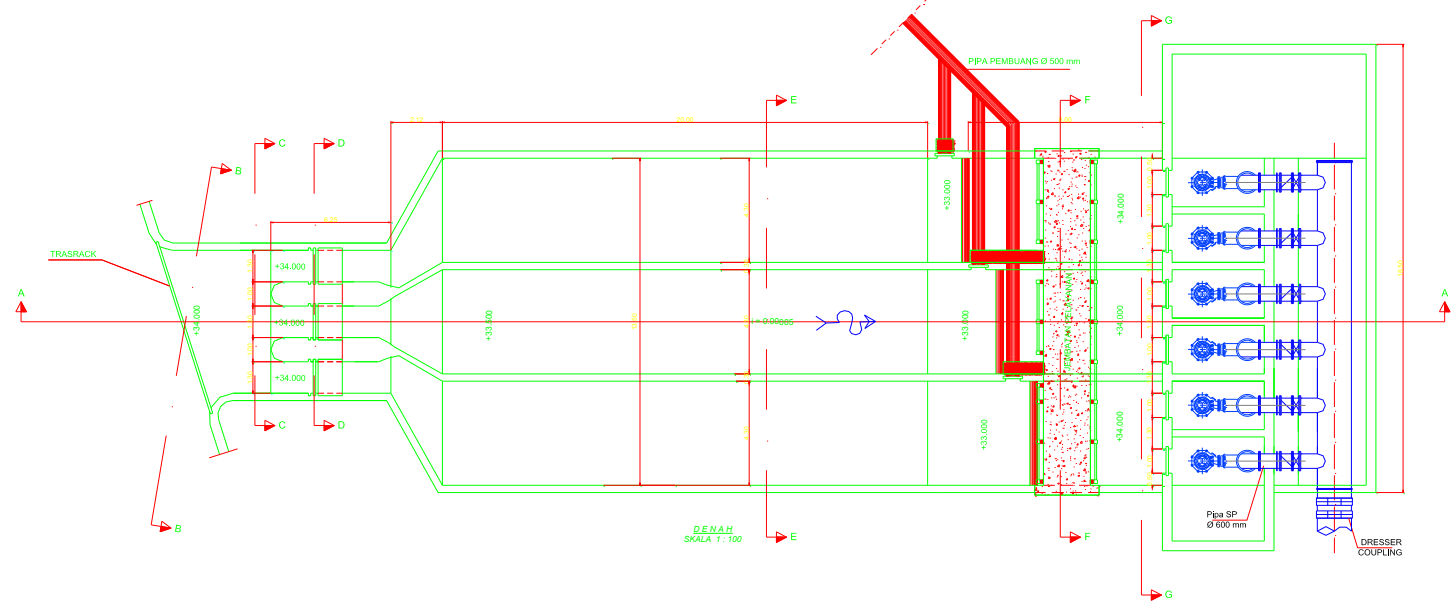

Gambar 2. Denah Bangunan Pengambilan

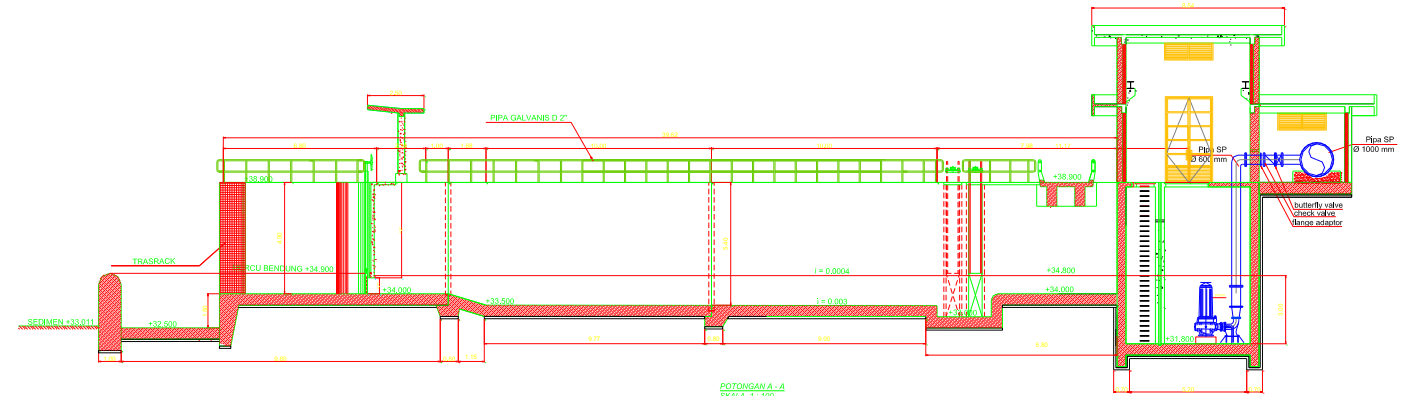

Gambar 3. Potongan Memanjang Bangunan Pengambilan

Seperti yang sudah diterangkan dimana bangunan pengambilan direncanakan dengan maksud untuk menyadap sebagian dari debit air sungai guna memenuhi kebutuhan layanan. Namun demikian, dalam perencanaan kapasitas pengambilan dipertimbangkan juga terhadap fleksibilitas pada kebutuhan yang lebih tinggi selama umur proyek (telah diperhitungkan dalam proyeksi kebutuhan air baku).

Kapasitas debit lubang pintu pengambilan air (intake) yang diperhitungkan sebagai dasar perhitungan hidrolis untuk pintu adalah sebagai berikut:

$$
Q=v \cdot b \cdot a \cdot \sqrt{2 \cdot g \cdot z}
$$

Dimana,

$\begin{array}{lll}\mathrm{Q} & = & \text { Debit aliran air }\left(\mathrm{m}^{3} / \mathrm{dt}\right) \\ \mu & = & \text { Koefisien debit }=0.80 \\ \mathrm{~b} & = & \text { Lebar bukaan pintu }(\mathrm{m}) \\ \mathrm{g} & = & \text { Percepatan gravitasi }\left(\mathrm{m} / \mathrm{dt}^{2}\right) \\ \mathrm{Z} & = & \text { Kehilangan tinggi energi }(\mathrm{m}) \\ \mathrm{a} & = & \text { Tinggi bukaan }(\mathrm{m})\end{array}$

Untuk perencanaan bangunan pengambilan, perhitungan didasarkan pada kebutuhan saat pengurasan dimana bangunan pangambilan dibagi atas dua ruang (kompartemen). Besar kebutuhan hanya untuk air baku yang akan diambil untuk pemopresan adalah 2200 liter setiap detiknya dan untuk pengurasan adalah 1100 liter setiap detiknya. Sehingga jumlah air baku seluruhnya adalah 3300 liter per detik atau $3.300 \mathrm{~m}^{3}$ per detik. 


$$
\begin{aligned}
& \text { Qd }=3.3 \mathrm{~m}^{3} / \text { det } \rightarrow \text { besar debit air baku yang masuk ke bangunan } \\
& \text { pengambilan } \\
& \text { g } \quad=9.81 \mathrm{~m} / \operatorname{det} 2 \rightarrow \text { besar percepatan gravitasi } \\
& \mathrm{m} \quad=0.80 \rightarrow \text { koefisien debit untuk bukaan dibawah permukaan air } \\
& \text { dengan z (KP 02:110) }
\end{aligned}
$$

Apabila data yang ada dimasukkan kedalam persamaan

Dengan memperhatikan:

$$
Q=v \cdot b \cdot a \cdot \sqrt{2 \cdot g \cdot z}
$$

1. Besar kecepatan aliran yang masuk ke bangunan pengambilan, $\mathrm{V}=1.1 \mathrm{~meter} / \mathrm{detik}$

2. Menurut KP 02:110, pada perencanaan yang normal bahwa untuk kecepatan aliran 1-2 meter per detik besar ukuran garis tengah butiran yang bisa masuk adalah 0.001-0.004 meter (10-40 mm)

3. Periksa ukuran butiran dengan memakai persamaan

$\mathrm{V}=10 \mathrm{x} \mathrm{d}^{0.5} \rightarrow \mathrm{d}=0.0121 \mathrm{~m}=12.1 \mathrm{~mm}$ (menurut KP 02:110 besar d adalah 10-40 mm)

4. Untuk mendapatkan tinggi z dipakai persamaan:

$$
V=v \cdot \sqrt{2 . g . z} \rightarrow 1.1=(0.80) \sqrt{(2)(9.81) z},
$$

Dengan memasukkan nilai yang ada maka diperoleh $\rightarrow \mathrm{z}=0.096 \mathrm{~m}=0.10 \mathrm{~m}$

5. Untuk mendapatkan tinggi pintu a dipakai persamaan:

$Q=v b a \cdot \sqrt{2 . g . z} \rightarrow 3.3=(0.80) b a \sqrt{(2)(9.81)(0.10)}$,

diperoleh $3.3=1.12057 \mathrm{~b}$ a

bilamana jumlah pintu dipakai adalah 3 dan lebar pintu dipakai $1.3 \rightarrow 3.3=4.37$ a

maka a $=0.76$ meter

6. Tinggi air di pintu adalah $0.76+0.10=0.86$ meter

7. Sekarang diperiksa besar debit yang dihitung dengan memasukkan nilai-nilai yang ada dan dengan memakai persamaan $Q=v b a \cdot \sqrt{2 \cdot g \cdot z}$

$$
\begin{aligned}
& Q=v b a \cdot \sqrt{2 \cdot g \cdot z} \\
& Q=(0.80)(3)(1.3)(0.86) \sqrt{(2)(9.81)(0.10)} \quad=3.75 \mathrm{~m}^{3} / \mathrm{det}
\end{aligned}
$$

Besar debit perhitungan adalah $3.75 \mathrm{~m}^{3} /$ det dan debit rencana adalah $3.3 \mathrm{~m}^{3} / \mathrm{det} \rightarrow \mathrm{OK}$

\section{Kesimpulan}

Dari hasil analisa yang dilakukan, maka diperoleh:

- Besar debit yang diharapkan untuk masuk ke bangunan pengambilan adalah $3.3 \mathrm{~m}^{3} / \mathrm{det}$, dimana nilai ini didasarkan pada kebutuhan.

- Untuk mencapai hal tersebut diperlukan pintu sebagai pengatur besar kecepatan aliran masuk dan jumlah aliran masuk.

- Jumlah pintu adalah sebanyak 3 buah yang memberikan pengaruh besar debit yang terjadi adalah $3.75 \mathrm{~m}^{3} /$ det.

\section{Daftar Pustaka}

Dake, JMK. (1989). Hidrolika Teknik. Jakarta: Penerbit Erlangga.

Sasongko, Dj. (1989). Teknik Sumber Daya Air I.Jakarta: Penerbit Erlangga.

Sosrodarsono, S. (1989). Hidrologi Untuk Pengairan, Bandung

Suripin. (2008). Buku Ajar Hidrolika. Semarang: Departemen Teknik Sipil Universitas Diponegoro 